\title{
Doctor Distrust: Pragmatism, Intersectionality, and the Confluence of Expertise and Interests
}

\author{
Lawrence H. Williams ${ }^{1}$ \\ ${ }^{1}$ Department of Sociology, University of Toronto, Toronto, Canada. \\ Correspondence: Lawrence H. Williams, MA, Department of Sociology, University of Toronto, 725 Spadina Avenue, \\ M5S 2J4, Toronto, Canada.
}

Received: September 28, 2017

Accepted: October 19, $2017 \quad$ Available online: October 31, 2017

doi:10.11114/ijsss.v5i12.2748

URL: https://doi.org/10.11114/ijsss.v5i12.2748

\begin{abstract}
The idea that only experts can be privy to knowledge about the world has been strongly contested throughout recent history. Using interviews with 39 British seniors tasked to discuss the role of doctors in matters of life and death, I argue that distrust for expert knowledge stems largely from the belief that knowledge is deeply shaped by personal experience. However, such distrust is not absolute as respondents still hold some faith in medical expertise due to their own perceived lack of medical knowledge and experiences with the medical field. As such, I assert that respondents demonstrate ambivalence towards medical expertise due to the confluence of expertise and interests that they find in the role that doctors play in assisting individuals with their health. I connect my findings to the theoretical traditions of American pragmatism and intersectionality to demonstrate how the ambivalence demonstrated by respondents signals their tacit use of a combination of these theories or what I term pragmatic intersectionality.
\end{abstract}

Keywords: expertise, pragmatism, intersectionality, death and dying

\section{Introduction}

"It is quite conceivable that the modern age-which began with such an unprecedented and promising outburst of human activity — may end in the deadliest, most sterile passivity history has ever known" (Hannah Arendt, 1998, p. 322)

Faced with a world that experienced unparalleled growth in industry and knowledge, why might Arendt (1998) have had such a grim outlook on the future? In The Human Condition, Arendt (1998) claimed that along with the growth of the modern world came an increasing tendency to forget one's history. Because much of what may have been easily discernable to lay individuals has now been developed to the point where only experts have clear understanding, individuals are becoming increasingly unaware of the origins of the objects around them and the practices they enact (see Arendt, 1998; Weber, 1978). If this trend continues, wrote Arendt (1998, p. 5), individuals may indeed lose any initiative to "think what [they] are doing" and simply assimilate to the rules outlined before them.

But do individuals by and large believe experts? The idea that only experts can be privy to knowledge about the world has been strongly contested throughout the $20^{\text {th }}$ century. Critiques are found in several domains of expertise ranging from medicine (Donohue, Huskamp, Wilson, \& Weissman, 2009) to education (Trow, 1996). Central to these critiques are two ideas: experts are interested in furthering their own agendas (Whyte \& Crease, 2010); and the lived experiences of individuals cannot be captured into generalized models (Haraway, 1988). While often framed in terms of general distrust in medical expertise or the use of competing logics in a "negotiated order" (see Madden \& Sim, 2016, p. 88; Strauss, 1976), I argue that it is important to acknowledge that two lines of thought have been paramount in supporting the tacit assumptions present in these critiques: American Pragmatism and Intersectionality. Together, these two line s of thought have provided philosophical grounds for critiquing the idea that sole groups of persons can have general expertise due to their shared claims regarding the situated and fundamentally subjective nature of knowledge and experience (Williams, 2017a). Thus, the reasons for negation that scholars such as Madden and Sim (2016) highlight are due to individuals having arrived at the conclusion that doctors' claims and judgments are not sacrosanct.

To demonstrate the coupling of pragmatist and intersectional logic in practice, I analyze interviews with individuals who were asked to think about how terminally-ill individuals may make the decision to prolong their lives or die naturally. Through my analysis, I find that individuals often believe that doctors are dismissive of patients' understandings. While not necessarily demanding that doctors cater to patients' desires completely, respondents tend to 
agree that doctors should incorporate patients' needs, wants, and understandings more fully into the decisions they make about their health and well-being. Overall, while respondents tend to have faith in both doctors' commitment to their patients as well as in their medical expertise, they demonstrate ambivalence due to seeing doctors as not having access to the same lived experiences as their patients. I assert that this lack of shared experience, coupled with doctors' alleged tendency to minimize the viewpoints of their patients, demonstrates respondents' pragmatically intersectional view of expertise: Rather than either wholly accepting or rejecting medical expertise, respondents tend to see the applicability of medical expertise to specific patients in a complex manner. While doctors may sometimes know what is best, being attentive to concerns of patients may enable better care to be provided. In short, respondents tend to assert that the attention doctors need to pay to patients' perspectives relies on the case at hand and, thus, questions of expertise or knowledge in general matter less than the realities of the issues confronting patients.

Connecting these findings directly to a core claim of intersectionality, which is that aspects of the environment or individuals' lives cannot be studied in a piecemeal fashion, but as they interlock, intersect, and chemically combine (Brah \& Phoenix, 2004; Crenshaw, 1990; McCall, 2005), will enable me to discuss further how the concepts of humanity or society have also become particularized by some individuals into that of human groups, much akin to Weber's (1978, p. 302) "status groups." Rather than see humans in general as possessing different amounts of discrete and bounded knowledge, respondents tend to see such knowledge as deeply funded by specific life experiences, investments, and interests (see Durkheim, 1995; Tocqueville, 2002). This view extends into an intersectional reading of Weber's (1978, p. 302) "status group" concept as respondents also tend to see doctors' use of medical expertise as not stemming solely from clear professional interests, but often from doctors' genuine beliefs that they are privy to the conditions of their patients at a level beyond their patients' comprehension.

\section{Pessimism about the Human Condition}

Having witnessed the Eichmann trial, Hannah Arendt (1963) wondered what could drive people to commit monstrous acts such as those that happened in the heydays of Nazi Germany. Given the testimony of Eichmann, she argued that heinous actions were likely the result not of personal evil, but of bureaucracy. By being given relatively small and technical tasks, individuals even the most violent of regimes could be at such a distance from what their actions, en masse, were doing that they could claim to legitimately feel no responsibility (Arendt, 1963).

Echoing Weber (1978) and anticipating many scholars of bureaucracy's claims regarding the pitfalls of increasingly bureaucratic nations (see Tocqueville, 2002; Mills, 2000; Putnam, 2000), Arendt (1998) put forth a pessimistic view of the human condition in in the twentieth century. Key in this pessimism was the idea that, through increased distance between individuals, actions would become more banal for persons as they lost sight of the impact that these actions would have on others (Arendt, 1963). Arendt (1998) took this critique to members of the academy and the public at large. For instance, she claimed that the tendency to work towards bettering the human condition by expanding the scope of possible actions for the human race (such as going to the moon, etc.) had been eclipsed by a focus on personal desires (Arendt, 1998). Individuals were becoming focused more on furthering their own interests rather than that of their fellows, leading to a condition in which political concerns for all gave way to political concerns for oneself (Arendt, 1998).

I assert that these sentiments are conceptually analogous to what Weber referred to as "status groups." Weber (1978) claimed that individuals could be categorized according to the various interests that they held and the social statuses that they occupied in the eyes of others in their societies. What Arendt (1998) discusses in terms of the banality of interest maps onto these categories quite closely. For example, she states that rather than work towards the common good, or even towards a possible good (see Anderson, 1991; Ryan, 1996), individuals work towards what they consider to be their own interests. While they may do so in the name of humanity at large - such as focusing on health or socio-economic well-being - the focus of their attention is on aspects of life that are inseparable from their own lifeworlds (see Habermas, 1984) or interests. As such, through a shift from a forward-looking, grand, and ambitious outlook on the bounds of humanity gradually becomes replaced by a present-centred and narrow outlook on what humans can and should do.

Such ideas regarding the present-centred nature of action are reinforced by pragmatist and intersectional theories which demand stark focus on the lived, everyday experiences of individuals and the diminishment of grand, "abstract" theories of both the human condition as it currently stands and has evolved (see Mills, 2000) as well as what it can potentially become.

\subsection{Pragmatism: The Myth of Stability}

Pragmatism emerged in the late $19^{\text {th }}$ century in the United States of America. While first penned by William James in 1890, it is often credited to the work of Charles Sanders Peirce. In brief, pragmatism is a branch of philosophy that is inspired largely by Hume, as made evident in its skepticism of a priori categories and fixed ways of understanding 
(James, 1981; Whitford, 2002). For example, one leading pragmatist James Dewey (1988) argued that individuals' categories of perception are best seen as akin to habits. Based on one's experiences with the world, one forms ways of seeing and sensing external stimuli. Because these are ultimately derived from experience with the external world, their a priori status must be seen as recursive. New experiences should be able to change the shape and function of these categories, thus making their a priori status something that is ultimately present focused (Dewey, 1988; Joas, 1996; Whitford, 2002).

The idea of present focused categories and habits was strongly promoted by the social behaviourist George H. Mead. In his Self and Society, Mead (1934) argued that all of an individual's perceptions are the product of an ongoing inner dialogue between one's active self - one's "I" - and the stored experiences and views of other members of their society - one's "Me's." Because this dialogue is ongoing, and because this dialogue influences all of one's perceptions, perception itself must be seen as ongoing. It must also be seen as present-focused because of the fact that this inner dialogue occurs when one is presented with some kind of stimulus, and cannot be entirely controlled. In short, individuals establish meanings based their particular renderings of stimuli in the moment of perception, not beforehand.

Such a theory opens up space for seeing perception as possibly limitless in terms of novel understandings - if meaning is made at each moment of perception, and is done so through the process of dialogue between an immanent sense of agency (one's 'I") and a repository of heuristic beliefs that one has amassed over time (one's various, domain-specific and ever-evolving 'Me's), then each stimuli presented to an individual can be perceived in many possible ways based on the contours of each specific moment of perception. For example, Whitford (2002) used the ideas of Mead and present-focused perception to challenge a central tenet of many economic theories of action: The idea that individuals hold stable preferences, and that these preferences are used rationally by individuals in order to make decisions. While one may interpret such a claim as being in line with Mead, in so far as these stable preferences may be stored in one's "Me's" or repositories of collective ideas, Whitford (2002, p. 338) used Mead's present-focus to assert that one's preferences are not held as such, but rather emerge in real situations and problematic scenarios. That is, rather than picture individuals as consciously selecting lines of actions based on any preferences that they have, Whitford (2002) claims that, a la Mead and Dewey, individual action is better characterized as a stimulus response that is funded by one's various stocks of knowledge in the moment. Because the moment of action is centered on the present, the constraining effects of one's context, one's mood (Silver, 2011), and myriad other factors can come into play and fundamentally change the shape of one's preferences. In this sense, preferences are not ends or goals that people store, but rather are ends-in-view that one can continually change both over time and spontaneously in the moment.

\subsection{Intersectionality: Chemically Emergent Groups and Selves}

The idea that people do not possess any meaningfully discrete and stable preferences, and that decisions are fundamentally present-focused are assumptions deeply woven into work of the intersectionality perspective. However, this perspective differs from pragmatism regarding its assumptions about what stable ideas or "portfolios" are composed of (Whitford, 2002, p. 336). Rather than see individuals' experiences as loosely funding one's perception, leaving it quite open to new renderings and interpretations, intersectionality sees one's experiences as chemically combining into matrices which work to create new baselines for future experiences (Collins, 2000, p. 18). Only by understanding the internalization of experience as crystallizing into tangible matrices can researchers understand, claim intersectionality scholars, the longstanding realities of inequality and other forms of oppression. Individuals who have experienced discrimination, for example, enter into situations knowing at risk of being perceived differently based on who they are, as well as actually being seen differently by others due to various societal understandings about the credibility of certain persons over others in terms of various norms such as ability (Steele, 1997), beauty (Drury \& Louis, 2002), national belonging (Kunst, Tajamal, Sam, \& Ulleberg, 2012), and respectability (Campbell \& Gibbs 2009). Thus, while individuals may not have stable preferences, they do have relatively stable expectations due to their cognizance of the fact that they live in relatively stable and stratified worlds.

Such differences between pragmatism and intersectionality come into stark relief when turning to the latter's founding. According to Crenshaw (1990), a legal scholar widely accredited with bringing the term into social science, intersectionality takes seriously the ways in which individuals cannot be understood as the sum of their various roles or social identities, but as a complex matrix of interlocking roles or social identities. In other words, a black woman is not simply black plus woman, but black and woman, implying a multiplicative rather than an additive effect. Seeing individuals as complex configurations of various social categories, thus, bears a striking contrast to the view of Mead (1934) presented earlier and pragmatists in general. Given societies' various legacies of discerning between individuals based on ascribed and accumulated characteristics - such as age, race, and gender in the former and income, work experience, and education in the latter - the pragmatist view of potentially limitless action becomes tightly bounded in the intersectional perspective. While intersectionality by no means frames individual action as determined, by specifying the parameters of both individuals' own subjective renderings of future events based on the gestalt of who 
they are, where they are, and what time they are in as well intersubjective dimensions of experiences which cause individuals to be rendered in certain ways and not others, this perspective explicitly theorizes a "portfolio" or baseline of experience that pragmatists like Whitford (2002) explicitly attempt to theorize out of perception and action.

A tension thus exists between these two perspectives regarding the extent to which not only previous experiences fund one's perception or sense of agency, but also the extent to which one's surrounding environment shapes these processes. By grounding perception in firmly in specific social configurations, intersectionality thus extends the pragmatist emphasis on action (see Dewey, 1988) by seeing the creativity of action (see Joas, 1996) as being in closer relation to the situations it occurs in. In other words, the internal dialogue (see Archer, 2007) so central to pragmatist thought moves from being strongly present-centered and focused on resolving current issues, to more fully incorporating previous experiences and understandings that enable one to act in ways that we be fruitful given one's social milieu and all of the expectations and biases involved in this process.

\section{Pragmatically Intersectional: Critiquing Experts}

The idea that thought and action are indeed present-focused but informed by the fact that individuals are complex configurations of the multiple spaces they inhabit and the contexts they have internalized supports ideas regarding the shortcomings of 'objective' knowledge (see Harraway, 1988, p. 575). Ranging from critiques of the concept of objectivity as ignoring the role of power and subjectivity in shaping what gets deemed truth to critiques focused on the dynamic nature of knowledge and social relations, objectivity and objective analysis are seen as snapshots of an ongoing process of meaning-making and becoming rather than ideal outcomes for research (Haraway, 1988; Kondo, 1990)

For example, Madden and Sim (2016) discuss how, rather than passively take heed of doctors' warnings and diagnoses, patients often negotiate and contest information provided to them. Key in this view is that individuals are not automatically labeled (see Lemert, 1951) by doctors when diagnosed, as they maintain the capacity to reject diagnosis (Madden \& Sim, 2016, p. 90). Beck, Bonss, and Lau (2003) argue that this sort of negotiation is a key aspect of life in the contemporary era in Western societies, as individuals no longer are guaranteed the security of established roles. Applied to the case of doctor-patient relations, this means that individuals more often question advice, though simultaneously tending to seek it out more often than in the past (Khoo, Babl, Jury, \& Goldman, 2008). This is done in part due to increased use of the internet to seek out information on a wide range of topics extending far beyond the purview of health (Khoo et al., 2008).

The increases in the negotiation with and the seeking out of medical expertise have thus contributed to a state of distrust in medical expertise relative the past. However, as individuals are increasingly seeking out expertise online, this indicates that it is not expertise in general that is being rejected, but individual experts' particular assessments. In a time of socio-economic and political flux (see Potter, 2015), such behavior can be made sense of in that individuals perceive their environments as risky and, hence, want to be more fully informed than they may have in more stable times (Swidler, 1986). Feeling relatively unsettled (Swidler, 1986), individuals increasingly want to cast wide nets when seeking expertise while simultaneously seeking out expertise more often on any given matter due to the changing nature of their everyday realities causing them to distrust their own intuitions and knowledge about important events. The waning of both time spent in and time structured by formal institutions - such as the workplace - leads individuals to be more fully in the public sphere (see Rose, 1990). As a result, individuals approach public authority figures with skepticism despite, as noted by Arendt (1998), their increasingly banal outlook on everyday life and tacit acceptance of much of what institutions and systems of authority present to them.

\section{Data and Methods}

To assess the extent to which individuals think and act in pragmatically intersectional terms, I analyze interviews with individuals tasked to think about the role of doctors in decisions about life prolongation and dying. Given the tension between medical expertise on the one hand and individuals' own recognitions of their health and well-being on the other, this case provides useful terrain for examining how individuals conceptualize expertise in light of personal concerns (see Archer, 2007).

The data for this study are part of a secondary qualitative dataset collected by Gary Bellamy and Jane Seymour on attitudes towards death and dying. The data I am analyzing are 39 interviews conducted with individuals living in Sheffield, United Kingdom, 38 of which are over the age of 65 and all identifying as White British. Respondents were healthy individuals sampled randomly by a pool of general practitioners in the Sheffield area.

Respondents were given a series of vignettes about a fictional couple - Frank and Mary - tasked to make decisions regarding whether to have their lives prolonged in the wake of serious illness. I focused on a vignette in which Frank was unconscious as a result of serious lung cancer that he was diagnosed with, leaving Mary to decide whether he 
should have his life prolonged or "die naturally."

To assess the interviews, I use the analytical technique narrative analysis (Hollway \& Jefferson, 1997). This method directs researchers' attention to the ways in which respondents construct narratives when answering questions, as such shifting attention away from specific details to the contexts in which these details are presented. As I am interested in examining the rationales respondents provide for either trusting or distrusting the advice of doctors, contextual izing their claims about doctors' expertise within narratives they construct regarding their own valuation of life, view of expertise in general, and understanding of death and dying will enable me to gauge how well both pragmatic and intersectional understandings are present in their responses.

\section{Analysis}

Respondents varied in terms of the implicit and explicit levels of trust they expressed in both the medical establishment and individual doctors. I found that 3 main themes were present in the interviews regarding the role of doctors in making assessments about individuals' health, well-being, and quality of life. They tend to occur for respondents in the following order:

1) The Prolongation of Life: Here, doctors are seen as always wanting to maintain life. This theme is prompted by variants of the following question: "Given Frank's situation, do you think it's natural to want to prolong life at all costs?" When asked this question, respondents tended to specify the question in terms of doctors wanting to prolong life at all costs, and believed that while not always justified, such a belief is sensible given doctors' commitment to health.

2) Doctors' Expertise: After discussing how natural the desire to prolong life is, many respondents then went on to discuss the role of doctors' medical expertise in shaping this issue. For some respondents, doctors were justified in prolonging life due to having expert knowledge. Howe ver, other respondents believed that doctors ignored relevant experiences and knowledge of patients when making estimations of their own.

3) Doctors' Openness: In this last theme, respondents demonstrate ambivalence over the extent to which they believe doctors are willing to negotiate their own understandings of health given patients' understandings.

\subsection{Doctors' Expected Desires}

Prompted by a question regarding the desire to prolong life, respondents tended to first think about how and why doctors played a role in maintaining the lives of others. For some respondents, this caused them to focus on doctors' training as well as their general desire to maintain patients' health. For example, Alice claimed that 'it seems to be natural for doctors to want to do that" given that 'they say 'We're trained to save life, not to end it' But I somet imes think they go o verboard, as they did with my mother-in-law." Similarly, Eddy made the following claims about doctors' desires to prolong the lives of patients based on likely expectations of the profession:

Yeah, it's natural for doctors, 'cos that's their job, that's what the Hippocratic oath tells 'em to keep people alive as long as possible: it wants changing actually because [chuckles] about when some of these people, I mean I've heard about people, they've been ... they've been dead for weeks and weeks and they still treating 'em.

Thus, for these respondents it is "natural" for doctors to desire to prolong lives due to them having taken the Hippocratic oath. Both Alice and Eddy do not actually think that doctors should always do this, as noted by statements they make later about how these desires can lead doctors to sometimes push patients beyond their limits. However, before making such assessments they see life prolongation as more of a question about doctors' desires than anything else.

While doctors' roles surfaced first Alice and Eddy, Leon first thought of religiosity as a considering factor for the ending of one's life. In response to the question of life prolongation as always being natural, Leon stated that he does not think it is natural 'because I'm not religious, I don't believe in religion...I couldn't believe there was such a thing as a God that makes people die of cancer and things like that. That didn't seem sensible to me." Thus, rather than frame life prolongation around doctors, Leon first thinks of religion. When he does talk of doctors, however, he does appear to follow the same logic as Alice and Eddy by stating that, even though he thinks "it's a waste of time" to try and save patients that are too far gone, doctors are "trying, aren't they? Doctors are trying." Thus, despite seeing issues of life prolongation more in terms of religion than medical expertise, Leon still sees doctors' desires to save life as, if not noble, then at least benign.

\subsection{Doctors 'Misguided Desires}

However, this of the natural elements of desiring to prolong life led some respondents to question whether doctors had the right to impose these desires onto their patients. Some respondents stated that doctors often tended to think that they knew more about the health of their patients than their patients themselves. For example, Alice stated the following in regards to the treatment of her mother-in-law: 
All those people working - doctors and nurses - putting themselves out and working like billy-o, even in the middle of the night, to stop her from dying, when really it was time for her to die. She was ready, she said at the end 'I want to go'. She couldn't stand it any longer, and I think to prolong that is a wicked thing to do. I hope they won't do it to me.

Barbara shared similar sentiments:

Yes, in a lot of cases [they are trying to do what is best]. If they know ... I don't agree with, erm, when they know that you've not got long to live - and when I mean long, not many weeks - I don't think they ought to do this. And I don't think, like my sister-in-law, they operated on her, and they knew that she wasn't going to get better anyway, and we all did. And it puts such hope into all us that you think: 'Oh, they've found out exactly where it is, the cancer', and she died a few days later: I don't agree with that. If they ... I know they're trying to do their best, but they're putting that person through ... through hell again, when they've already had one or two operations, you know.

This respondents' own experiences with loved ones who had "gone through hell" at the behest of doctors' advice to maintain their lives caused her to seriously distrust both the idea that doctors were privy to expertise beyond that of their patients and that they knew what was best for their patients. Furthermore, by questioning doctors' judgment in such ways, these respondents signal that they view doctors' desires through their presumed motives. Alice's claim that prolonging life in the way they did in her mother-in-law's case is a "wicked thing to do" implies that she doubts the motivations behind these actions. However, when respondents come to think about desire through motivation, they then start to see doctors' decisions as more difficult to make.

\subsection{Doctors 'Dilemmas: Balancing Expertise and Sympathy}

While respondents sometimes aired their distrust for doctors after thinking about these individuals' desired for maintaining patients' lives, doing so caused some of them to move on to a more ambivalent position. For example, Ian made the following statement upon being probed about his view that doctors should have sole discretion over their patients' health and whether doctors should discuss possible treatment options with patients:

I would think that the majority of people would be like me and be quite content to leave the decision and the judgement to the doctor, but there are some people I imagine who have very strong views about their right to influence the treatment that they have. And to be fair to those, I think the doctor should talk to Frank because the other people who would have confidence in the doctor anyway wouldn't be upset by the conversation.

Ian believes that "some people" might want to oppose their doctors' views and that, given the expertise that doctors have, engaging in dialogue with the doctor would be acceptable.

Similarly, Alice augmented her earlier claims regarding doctors doing a "wicked thing" to her mother-in-law by prolonging her life:

I don't know that for sure. I mean they probably didn't know about my mother-in-law, didn't ask her, I don't know. But I often think about that and I often think, if they'd known, would they have done what they did? And I don't think they should have done it anyway. It was quite clear she was dying.

Here Alice implies that she thinks doctors might have let her mother-in-law "go" if they knew the extent of her illness. While she remains unsettled by the doctors' attempts to preserve her relative's life in the face of what she considered to be clear evidence of her mother-in-law's irremediable condition, she does not believe the doctors necessarily acted out of malice or strictly in adherence to their own beliefs or interests.

\section{Discussion and Conclusion}

By mapping out the responses of individuals tasked to think about the role of doctors in prolonging the lives of patients, I have attempted to demonstrate how present-centered, ambivalent assessments of doctors' actions are made by a group of individuals that may be considered to be non-reflective and largely supportive of the medical industry (Donohue et al., 2010). As was shown, many respondents voiced serious concerns as to the reliability of the medical expertise. Many of the doubts about this expertise stemmed not from doubts about the medical industry or medical knowledge in general, but about the interests and potential motives of specific doctors. Specifically, doctors' lack of attention to patients' experiences and understandings were seen as undermining these professional's capacities to engage in due diligence. In turn, questions of expertise often were thought of in terms of questions of motive, and doctors and patients were seen as having different stakes (see Greco, 2012; Mik-Meyer, 2015). 
By viewing questions of expertise through the lens of motive, respondents signaled the inseparability of knowledge about health and wellness - and medical knowledge more broadly - from the specific interests of the individuals who mobilize this knowledge. Eddy's claims regarding doctors' simultaneous commitment to the Hippocratic Oath combined with their unfortunate tendency to continue to prolong the lives of individuals who have "been dead for weeks and weeks" speak to this issue directly. For Eddy, doctors are sometimes torn between doing what they think is right and taking a more holistic, patient-inclusive approach to service. In short, this respondent's claims represent the larger finding that respondents actively refract (see Durkheim, 1938) notions of expertise through the interests of the individuals' privy to such expertise. Part of this process, then, entails estimating which roles these individuals occupy, which interests they are trying to uphold, and how these compete with personal understandings or the patient's perspective.

The fact that respondents filter their perceptions of expertise through that of interest or subject location speaks to the logics of pragmatism and intersectionality. In line with pragmatism, respondents' recognition of the complex relationship between doctors' commitment to helping others with their commitment to maintaining life "at all costs" signals that they view life not in terms of abstract beliefs or discrete premises, but in more fluid terms. Doctors' interests were seen as multifaceted and uncertain rather than unambiguous. This ambiguity signals respondents' tacit intersectional understanding of doctors' work. By seeing doctors' as balancing competing expectations, respondents demonstrated that they viewed doctors not simply as medical experts or life preservers, but as conflicted health care providers.

As such, Arendt's (1998) claims regarding the potential for the limiting of the scope of human affairs due to the increasing banality of human action finds some support in my analysis. The mystique of medical expertise and the doctors who hold it was not found among the majority of respondents in this study. Instead, actors' and agencies' specific interests were seen to be at the core of both medical knowledge and doctors' roles. However, while the mystique was lost for many, respondents also tended to demonstrate deference to these experts. While they may have questioned doctors' motives, this was done in terms of recognition of complexity of motive rather than simple distrust in most cases. As such, rather than expertise itself being diminished by these respondents, it can better be seen as being contextualized - expertise still exists, and indeed is privy to greater degrees to certain individuals than to others, but it is not hermetically sealed or iron-clad. Respondents signaled that sometimes expertise could be contested, and that its intimate connection with interests was at the core of its contested nature. Thus, echoing Weber's (1978) claims regarding how individuals act not insolation but in demarcated status groups, respondents demonstrated that rather than see doctors as simply privy to a distinct set of knowledge that patients do not have, both doctors and patients have their own knowledges based on their subjective experiences. However, as respondents saw doctors' actions as rooted not specifically in their interests as doctors, that is as part of the medical establishment, but instead as rooted in their specific experiences and beliefs as individual doctors, the subjectification if these actors' knowledges attests to respondents' tacit belief in what I term human groups rather than status groups - doctors may attend to their own perspectives rather than those of their patients due to simply believing that they know more about their patients' health than their patients do. Respondents' alternation between seeing doctors as stubborn and seeing them as being open to patients' points of view implies that these individuals take a very pragmatically intersectional approach to doctor-patient interactions: they realize that in an attempt to do their jobs, doctors might marginalize patients' perspectives. However, doctors may realize they are not taking key information into consideration and, as such, change their own points of view on a case by case basis.

Seeing doctors as members of a human group rather than a status group when it comes to assessing their respect for patients' own opinions and knowledge about their health thus speaks to Whitford's (2002) claims regarding the utility of pragmatism for sociological explanations of individual thought and action. Rather than having clear conceptions of doctors' roles, motives, and interests, the interviews I analyzed demonstrated respondents' open and evolving conceptions of these factors (see Williams, 2016a, 2017b, 2017c). Again, while certain features remained somewhat stable across respondents - such as a general sense of reverence for medical expertise and a shared assumption that doctors tend to have patients' interests - the fact that respondents deliberated between their ideas about doctors based on their own experiences with and deliberations about them signals a more ongoing interpretative process. Respondents' recognized that both doctors' and patients' particular ends or goals may change as they connect with one another and, through learning one another perspectives, develop new understandings or means for action (see Whitford, 2002).

In sum, respondents' meaning-making trajectories demonstrate how their understanding of doctors' roles is shaped by both their understanding of what constitutes medical expertise and what constitutes being a doctor (see Williams, 2017d). Recognizing that expertise can sometimes be used as a tool to further one's interests, respondents demonstrated hesitance towards uncritical acceptance of doctors' orders and even their roles as health care providers. However, the display of some reverence towards the idea of medical expertise and the commitment that doctors had to helping others demonstrates the sustained belief in expertise by these individuals (see Calnan \& Rowe, 2008; Douglass \& Calnan, 2016). At the end of the day, respondents knew that they themselves were not doctors. Having not undergone the same 
training or experiences, they recognized that doctors likely did know more than they did about many aspects of their health. Respondents' attention to the confluence of expertise and interests, coupled with their focus on how lived experience shapes what one knows about oneself, however, tempered this belief and worked to produce ambivalence towards medical expertise and doctors. Doctors are thus somewhat distrusted by these respondents due to these respondents' lack of certainty about both doctors' knowledge and intentions (see Williams, 2016a, 2016b), despite their acceptance of their roles as health care providers. Both skepticism and mystique are maintained by these respondents' pragmatically intersectional analyses of the doctors who care for both them and their loved ones.

\section{References}

Ahmed, S. (2004). The Cultural Politics of Emotion. New York: Routledge Press.

Anderson, B. (1991). Imagined Communities: Reflections on the Origin and Spread of Nationalism (Revised edition). London: Verso.

Arendt, H. ([1958] 1998). The Human Condition, Second Edition. Chicago: The University of Chicago Press. https://doi.org/10.7208/chicago/9780226924571.001.0001

Arendt, H. (1963). Eichmann in Jerusalem: A Report on the Banality of Evil. New York: Viking Press.

Beck, U., Bonss, W., \& Lau, C. (2003). The Theory of Reflexive Modernization: Problematic, Hypotheses and Research Programme. Theory, Culture \& Society, 20(2), 1-33.

Brah, A., \& Phoenix, A. (2004). Ain’t I a woman? Revisiting intersectionality. Journal of International Women's Studies, $5(3), 75-86$.

Calnan, M., \& Rowe R. (2008). Trust Matters in Healthcare. Buckingham: Open University Press.

Campbell, C., \& Gibbs, A. (2009). Stigma, gender and HIV: Case studies of intersectionality. In: Boesten, J., \& N. K. Poku (eds.). Gender and HIV/AIDS: Critical Perspectives from the Developing World. Ashgate, Surrey, UK, 29-46.

Collins, P. H. (2000). Black Feminist Thought, secondedition. New York: Routledge.

Crenshaw, K. (1991). Mapping the margins: Intersectionality, identity politics, and violence against women of color. Stanford Law Review, 43, 1241-1299. https://doi.org/10.2307/1229039

Dewey, J. ([1922] 1988). John Dewey, The Middle Works, 1899-1924: Human Nature and Conduct, 12. Carbondale: Southern Illinois University Press.

Donohue, J. M., Huskamp, H. A., Wilson, I. B., \& Weissman, J. (2009). Who do older adults trust to provide information about prescription drugs? The American Journal of Geriatric Pharmacotherapy, 7(2), 105-116. https://doi.org/10.1016/j.amjopharm.2009.04.005

Douglass, T., \& Calnan, M. (2016). Trust matters for doctors? Towards an agenda for research. Social Theory \& Health, forthcoming. https://doi.org/10.1057/s41285-016-0010-5

Drury, C. A. A., \& Louis, M. (2002). Exploring the association between body weight, stigma of obesity, and health care avoidance. Journal of the American Academy of Nurse Practitioners, 14(12), 554-561. https://doi.org/10.1111/j.1745-7599.2002.tb00089.x

Durkheim, E. ([1895] 1938). The Rules of Sociological Method. Chicago: University of Chicago Press.

Durkheim, E. ([1912] 1995). The Elementary Forms of Religious Life. Mineola, NY: Dover Publications.

Evans, J. S. B. T. (2012). Spot the difference: Distinguishing between two kinds of processing. Mind and Society, 11, 121-131. https://doi.org/10.1007/s11299-012-0104-2

Greco, M. (2012). The classification and nomenclature of 'medically unexplained symptoms': Conflict, performativity and critique. Social Science and Medicine, 75(12), 2362-2369. https://doi.org/10.1016/j.socscimed.2012.09.010

Habermas, J. (1984). The Theory of Communicative Action, Volume 2 Lifeworld and System: A Critique of Functionalist Reason. Boston: Beacon Press.

Haraway, D. (1988). Situated knowledges: The science question in feminism and the privilege of partial perspective. Feminist Studies, 14(3), 575-599. https://doi.org/10.2307/3178066

James, W. ([1890] 2007). The Principles of Psychology, Volume 1. New York: Cosimo Classics.

James, W. ([1907] 1981). Pragmatism. Indianapolis: Hackett Publishing Company.

Joas, H. (1996). The Creativity of Action. Chicago: The University of Chicago Press.

Johnson, S. D. Jr. (1987). Knowing that versus knowing how: Toward achieving expertise through multicultural training 
for counseling. The Counseling Psychologist, 15(2), 320-331. https://doi.org/10.1177/0011000087152010

Khoo, K., Bolt, P., Babl, F. E., Jury, S., \& Goldman, R. D. (2008). Health information seeking by parents in the internet age. Journal of Paediatrics and Child Health, 447-448, 419-423. https://doi.org/10.1111/j.1440-1754.2008.01322.x

Kondo, D. K. (1990). Crafting Selves: Power, Gender, and Discourses of Identity in a Japanese Workplace. Chicago: University of Chicago Press.

Kunst, J. R., Tajamal, H., Sam, D. L., \& Ulleberg, P. (2012). Coping with Islamophobia: The effects of religious stigma on Muslim minorities' identity formation. International Journal of Intercultural Relations, 36, 518-532. https://doi.org/10.1016/j.ijintrel.2011.12.014

Madden, S., \& Sim, J. (2016). Acquiring a diagnosis of fibromyalgia syndrome: The sociology of diagnosis. Social Theory \& Health, 14(1), 88-108. https://doi.org/10.1057/sth.2015.7

McCall, L. (2005). The complexity of intersectionality. Signs, 1771-1800. https://doi.org/10.1086/426800

Mik-Meyer, N. (2015). The social negotiation of illness: Doctors' role as clinical or political in diagnosing patients with medically unexplained symptoms.' Social Theory \& Health, 13(1), 30-45. https://doi.org/10.1057/sth.2014.15

Mills, C. W. (2000 [1959]). The Sociological Imagination. New York: Oxford University Press, Inc.

Putnam, R. D. (2000). Bowling Alone: The Collapse and Revival of American Community. New York: Simon \& Schuster. https://doi.org/10.1145/358916.361990

Raju, P. S., Lonial, S. C., \& Mangold, W. G. (1995). Differential effects of subjective knowledge, objective knowledge, and usage experience on decision making: An exploratory investigation. Journal of Consumer Psychology, 42(2), 153-180. https://doi.org/10.1207/s15327663jcp0402_04

Rupp, G. (2016). Rethinking the assumptions of refugee policy: Beyond individualism and the challenge of inclusive communities. Journal on Migration and Human Security, 4(3), 76-82. https://doi.org/10.14240/jmhs.v4i3.63

Ryan, S. (2006). Language learning motivation within the context of globalization: An 12 self within an imagined global community. Critical Inquiry in Language Studies: An International Journal, 3(1), 23-45. https://doi.org/10.1207/s15427595cils0301_2

Silver, D. (2011). The moodiness of action. Sociological Theory, 29, 199-222. https://doi.org/10.1111/j.1467-9558.2011.01394.x

Steele, C. M. (1997). A threat in the air: How stereotypes shape intellectual identity and performance. American Psychologist, 52(6), 613-629. https://doi.org/10.1037/0003-066X.52.6.613

Strauss, A. (1976). Negotiation: Varieties, Contexts, Processes and Social Order. San Francisco, CA: Jossey-Bass.

Tocqueville, A. D. ([1835] 2002). Democracy in America. PA: The Pennsylvania State University.

Trow, M. (1996). Trust, markets and accountability in higher education: A comparative perspective. Higher Education Policy, 9(4), 309-324. https://doi.org/10.1016/S0952-8733(96)00029-3

Weber, M. (1978). Economy and Society: An Outline of Interpretive Sociology. Berkeley: University of California Press.

Whitford, J. (2002). Pragmatism and the untenable dualism of means and ends: Why rational choice theory does not deserve paradigmatic privilege. Theory and Society, 32, 325-363. https://doi.org/10.1023/A:1016232404279

Whyte, K. P., \& Crease, R. P. (2010). Trust, expertise, and the philosophy of science. Synthese, 177, 411-425. https://doi.org/10.1007/s11229-010-9786-3

Williams, L. H. (2016a). Active intuition: The patterned spontaneity of decision-making. Presented at the 111th Annual Meeting of the American Sociological Association. http://citation.allacademic.com/meta/p1120670_index.html.

Williams, L. H. (2016b). Talk of pedophilia: The reflexive management of desire. Deviant Behavior, 0, 1-13. Available online: https:// doi.org/10.1080/01639625.2016.1257880

Williams, L. H. (2017a). Flattening experience: Song lyrics and evaluation of crisis. Journal of Poetry Therapy 30(2): $120-128$.

Williams, L. H. (2017b). From conscious values to tacit beliefs: Assessing Parsons' influence on contemporary sociology." Frontiers in Sociology, 2(10), 1-12. https://doi.org/10.3389/fsoc.2017.00010

Williams, L. H. (2017c). Thinking through death and employment: The automatic yet temporary use of schemata in everyday reasoning. European Journal of Cultural Studies, 0, 1-18. Available online:

Williams, L. H. (2017d). Turning inward: Tocqueville and the structuring of reflexivity. Journal of Critical Realism 0: 
1-16. Available online: https://doi.org/10.1080/14767430.2017.1370661

\section{Copyrights}

Copyright for this article is retained by the author(s), with first publication rights granted to the journal.

This is an open-access article distributed under the terms and conditions of the Creative Commons Attribution license which permits unrestricted use, distribution, and reproduction in any medium, provided the original work is properly cited. 